\title{
SAND95-0911C
}

\section{Ion Beam Surface Treatment: A New Technique For Thermally Modifying Surfaces Using Intense, Pulsed Ion Beams}

\author{
R. W. Stinnett, R. G. Buchheit, E. L. Neau, M. T. Crawford, K. P. Lamppa, T. J. Renk \\ Sandia National Laboratories \\ Albuquerque, NM 87185-5800
}

John B. Greenly, Ian Boyd, M. O. Thompson

Cornell University

Ithaca, NY 14853

\author{
D. J. Rej, Los Alamos National Laboratory \\ Los Alamos, NM 87545
}

\begin{abstract}
The emerging capability to produce high average power (10-300 kW) pulsed ion beams at 0.2-2 $\mathrm{MeV}$ energies is enabling us to develop a new, commercial-scale thermal surface treatment technology called Ion Beam Surface Treatment (IBEST). This new technique uses high energy, pulsed ( $\leq 500 \mathrm{ns)}$ ion beams to directly deposit energy in the top 1-20 micrometers of the surface of any material. The depth of treatment is controllable by varying the ion energy and species. Deposition of the energy in a thin surface layer allows melting of the layer with relatively small energies (1-10 J/cm2) and allows rapid cooling of the melted layer by thermal conduction into the underlying substrate. Typical cooling rates of this process $(109 \mathrm{~K} / \mathrm{sec})$ are sufficient to cause amorphous layer formation and the production of non-equilibrium microstructures (nanocrystalline and metastable phases). Results from initial experiments confirm surface hardening, amorphous layer and nanocrystaline grain size formation, corrosion resistance in stainless steel and aluminum, metal surface polishing, controlled melt of ceramic surfaces, and surface cleaning and oxide layer removal as well as surface ablation and redeposition. These results follow other encouraging results obtained previously in Russia using single pulse ion beam systems.

Potential commercialization of this surface treatment capability is made possible by the combination of two new technologies, a new repetitive high energy pulsed power capability (0.2$2 \mathrm{MV}, 25-50 \mathrm{kA}, 60 \mathrm{~ns}, 120 \mathrm{~Hz}$ ) developed at SNL, and a new repetitive ion beam system developed at Cornell University.
\end{abstract}

\section{Introduction}

Recent advances in high average power, pulsed ion beam systems are enabling a new technology to achieve rapid melt and resolidification of surfaces. Researchers at Sandia National Laboratories and Cornell University have developed the capability to produce $5-350 \mathrm{~kW}$ average power, pulsed ion beams at $0.2-2 \mathrm{MeV}$ energies using a repetitively pulsed (up to $120 \mathrm{~Hz}$ ) concept designed for long component lifetimes. This new capability is enabling us to develop a commercial-scale thermal surface treatment technology called Ion Beam Surface Treatment (IBEST). This new technique uses high energy, pulsed (typically $\leq 200 \mathrm{~ns}$ ) ion beams to directly deposit energy in the top 2-20 micrometers of the surface of any material. The depth of treatment is controllable by varying the ion energy and species. Deposition of the energy in a thin surface layer (Figure 1) allows melting or vaporization of the layer with relatively small energies $\left(1-10 \mathrm{~J} / \mathrm{cm}^{2}\right.$ for metal surfaces) and allows rapid cooling of the melted layer by thermal diffusion into the underlying substrate. Solidification of metals at the cooling rates typical of this process $\left(10^{9} \mathrm{~K} / \mathrm{sec}\right)$ results in the production of non-equilibrium microstructures (nano-crystalline and metastable phases) in the surface layer. Experiments with both laser and ion beams ${ }^{1-8}$ have shown that surfaces produced by this rapid thermal quenching have significantly improved corrosion, wear, and hardness properties. A recent review article ${ }^{9}$ details the results of early single-pulse laboratory experiments using high power ion beams to produce both melting and resolidification and ablation and shock waves to produce enhanced surface properties. Results from these experiments include improvements in wear resistance in machine tools, and successful interface mixing of treated deposited layers. These previous results provide an encouraging background for new experiments demonstrating the broad applications of surface treatment with ions beams and the new capability to conduct this treatment on a commercial scale.

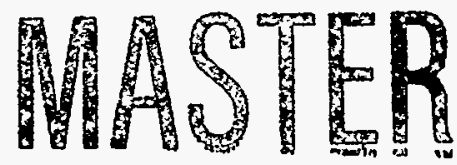




\section{DISCLAIMER}

Portions of this document may be illegible in electronic image products. Images are produced from the best available original document. 


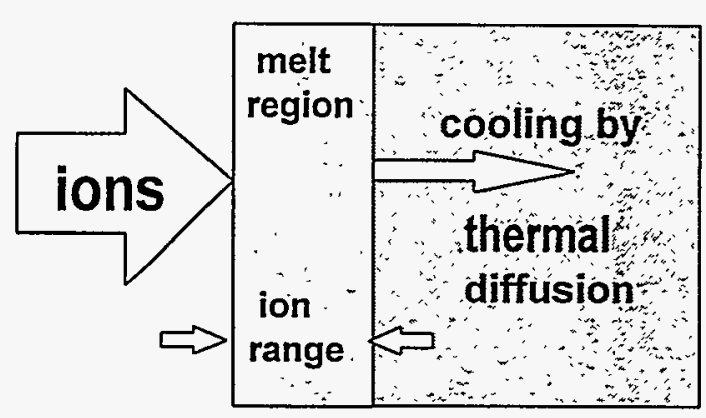

Figure 1. Ion BEam Surface

Treatment (IBEST) uses a

pulsed, high energy $(0.2-2 \mathrm{MeV})$

ion beam to deposit energy over

the classical ion range, typically

2-20 microns, in a surface, raising its temperature to melt.

Ion Beam Surface Treatment (IBEST) is a thermal process that does not significantly change the composition of the sample. The ion pulse rapidly heats a thin surface layer to melt using typically only $3 \times 10^{13}$ ions per pulse. Over the ion range the implanted ion concentration is less than $10^{-3}$ atomic percent. The short pulse length allows the heated depth to be confined to approximately the ion range by limiting the effect of thermal diffusion. Thermal diffusion lengths in $60 \mathrm{~ns}$ are 1 and 4 microns in stainless steel and aluminum respectively, less than the proton range in the materials at typical IBEST ion energies of $0.4-1 \mathrm{MeV}$. The use of a new Magneticallyconfined Anode Plasma (MAP) ion beam system ${ }^{10-13}$ described later allows any gas ion to be used to deposit energy in materials. Protons, having the largest range in materials, can provide relatively deep treatment ranging from 5-15 microns in aluminum for energies of 0.5 to $1 \mathrm{MeV}$ respectively.

The effects of Ion Beam Surface Treatment are similar to surface treatment using pulsed lasers but IBEST technology provides unique capabilities that allow it to avoid many problems intrinsic to pulsed laser technology, including poor energy coupling to metals, inefficient in-depth treatment, edge effects, and high cost. IBEST technology provides intrinsic in-depth energy deposition, large energy per pulse, low capital cost of hardware, and relatively high (15\%) wall-plug-to-surface electrical efficiency. Some advantages of IBEST over lasers are illustrated by Figure 2 .

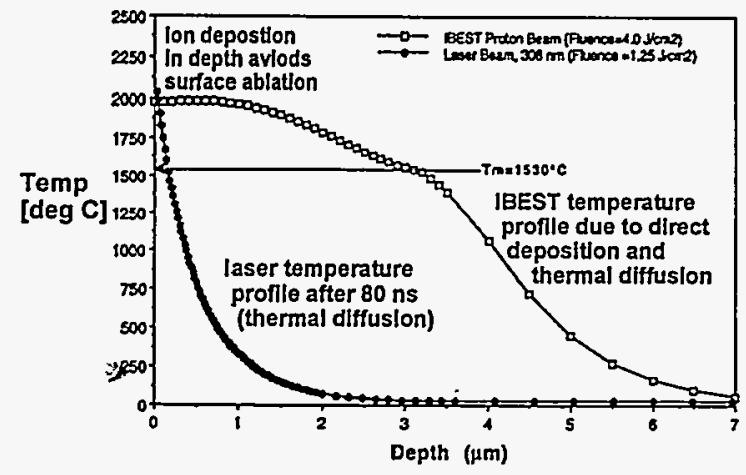

Figure 2. Pulsed ion beams deposit their energy efficiently in-depth, avoiding surface ablation while allowing relatively deep melting versus pulsed lasers. Parameters for RHEPP-I and carbon steel were used for this calculation.

The energy coupling of ion beams to a material is independent of the surface preparation and only weakly dependent on the actual material. The availability of a clean, single species ion source opens up new areas for metal studies, especially in the rapid solidification behavior of alloys. Thermal quench rates and solidification velocities can be controlled by varying the beam energy and the ion species.

The typical area treated by a single IBEST pulse ranges from $100-1000 \mathrm{~cm}^{2}$ depending on the application. This capability and our new repetitive pulse technology are key elements enabling high volume commercial applications.

\section{Results Of Initial Experiments}

IBEST experiments have been performed on several facilities including Sandia's Repetitive High Energy Pulsed Power (RHEPP) facility, Comell University's LION accelerator, and LANL's Anaconda accelerator. These experiments are supported by a team of researchers in pulsed power, beam physics, and materials science from Sandia National Laboratories, Cornell University, Los Alamos National Laboratories, and the UNM/LANL/SNL Advanced Materials Laboratory. Single-pulse and burst-mode tests at $1 / 3 \mathrm{~Hz}$ have been used to produce initial treated samples while hardware for full scale repetitive operation is being optimized. Results from initial analysis confirm surface hardening, amorphous layer and nanocrystalline grain size formation, metal surface polishing, 
controlled melt of ceramic surfaces, surface cleaning of hydrocarbon layers from 304 stainless steel, oxide layer removal, and corrosion resistance.

These initial experiments clearly demonstrate the ability of Ion Beam Surface Treatment to significantly enhance the surface properties of materials. The ion source for all of these initial experiments was a "flashover" source which produces a mixed species ion beam. Other experiments ${ }^{14}$ at Cornell University using this ion source have indicated that these beams are made up of approximately half $\mathrm{H}^{+}$ions and half heavier ions, predominantly $\mathrm{C}^{+}$ and $\mathrm{C}^{++}$. We have now begun treatment using the new, Magnetically-confined Anode Plasma ion source described later in this article. The following sections describe our initial experiments in more detail.

\section{Treatment O-1 Tool Steel}

These samples were treated using Cornell University's LION accelerator ( $1 \mathrm{MeV}, 4 \Omega, 40$ ns FWHM). The ion energy during the FWHM of the power pulse varied from approximately $0.5-1 \mathrm{MeV}$. The ion energy delivered to the surface was approximately $10(+/-30 \%) \mathrm{J} / \mathrm{cm}^{2}$ as measured by biased and apertured ion collectors and the load voltage monitor. The samples were located approximately $25 \mathrm{~cm}$ from the beam system. Treatment was done at a vacuum level of approximately $2 \times 10^{-4}$ torr.

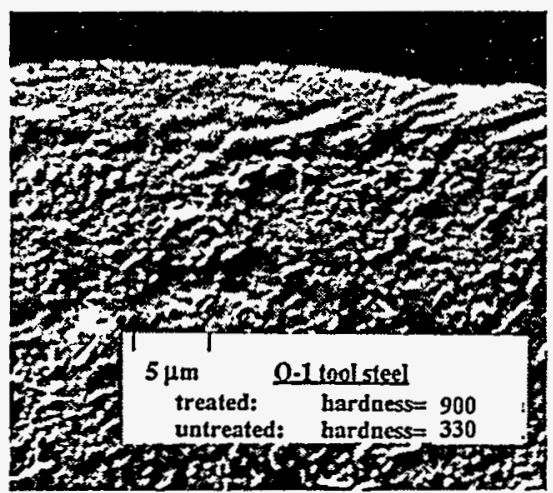

Figure 3. This cross sectional view of an O-1 tool steel sample shows the effects of rapid surface melting and cooling by a $50 \mathrm{~ns}$, $10 \mathrm{~J} / \mathrm{cm}^{2}, 0.5-1 \mathrm{MeV}$ mixed proton/carbon beam.

Cross-sections of IBEST-treated 0-1 tool steel samples were examined 15 using an optical microscope as well as cross-sectional and plan-view Transmission Electron Microscopy (TEM). An optical micrograph of the crosssection of an IBEST-treated sample is shown in Figure 3. The several microns nearest the surface of the sample were featureless. In contrast, the underlying untreated tool steel material had an equilibrium structure composed of $\alpha-\mathrm{Fe}$ (bcc-iron) and large iron carbides. The results of the optical metallography evaluation suggested that the iron carbides in the treated region had been largely redissolved into the bcc-iron matrix. The TEM examination of the IBEST-treated O-1 tool steel sample revealed that the near surface region of the sample was composed of microcrystalline grains approximately $20 \mathrm{~nm}$ in diameter. Hardness testing on the $\mathrm{O}-1$ tool steel samples was performed using a Shimadzu microindentation hardness tester. Knoop indentations were made using a $25 \mathrm{gr}$ load on the knoop tip yielding a Knoop hardness $\left(\mathrm{H}_{\mathrm{k}}\right)$ of $\mathrm{H}_{\mathrm{k}}=900$ for the treated surface and $\mathrm{H}_{\mathrm{k}}=330$ for the untreated surface of O-1 tool steel.

Both the optical metallography and TEM results indicate that carbon was dissolved into the Fe matrix during the pulsed beam treatment. The kinetics of the iron carbide dissolution process during heating, melting, and resolidification were apparently more rapid than the kinetics required for carbide reprecipitation during cooling. The presence of $\mathrm{FeO}$ in the treated layer suggests that oxide was incorporated into the layer from the oxidized, untreated surface when melting occurred during treatment. Oxygen may also have been incorporated during melting from the background gasses in the treatment chamber.

\section{Polishing of Ti-6Al-4V}

In other experiments we treated Ti- $6 \mathrm{Al}-4 \mathrm{~V}$ on the Anaconda accelerator ( $400 \mathrm{kV}$ peak voltage, $40 \mathrm{kA}$ total current, $500 \mathrm{~ns}$ pulse duration) at a treatment level of $7 \mathrm{~J} / \mathrm{cm}^{2}(+/-30 \%)$ at $250-400 \mathrm{keV}$ using a $400 \mathrm{~ns}$ ion pulse. The surfaces were treated using four pulses separated by at least 5 minutes between pulses. The untreated and treated surfaces are shown in Figure 4. 

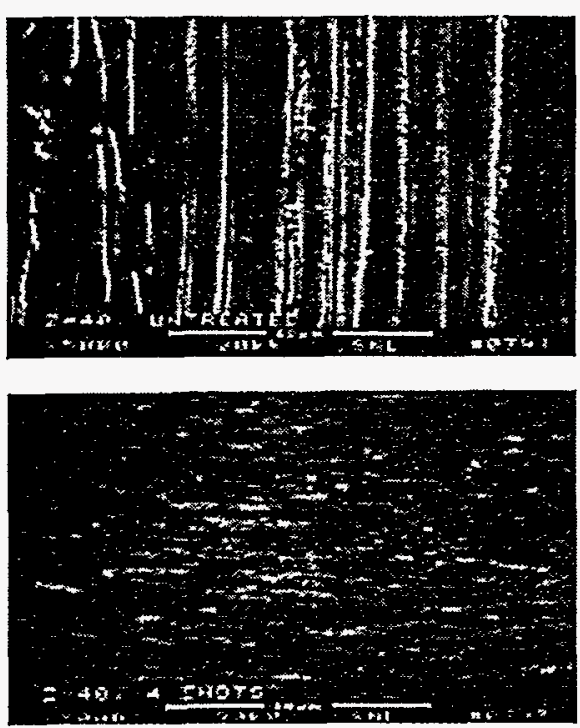

Figure 4. IBEST treatment of a Ti-6Al-4V machined surface (top) treated with $4,400 \mathrm{~ns}, 7$ $\mathrm{J} / \mathrm{cm}^{2}$ mixed proton and carbon beam pulses demonstrates significant surface smoothing to a 0.1 micron scale roughness.

The surface roughness of the untreated, machined surface was approximately 5 microns. IBEST treatment resulted in a reduction of roughness to 0.1 micron. The energy deposited in the top 3-4 microns of the near surface region in these experiments was more than sufficient to raise the temperature to the melting point and was likely large enough to cause some ablation of the surface. The time the surface was above the melting point can be roughly estimated from the energy deposition profile and the calculated thermal diffusion properties of the material to be $250-500 \mathrm{~ns}$.

\section{Corrosion Resistance}

Initial corrosion resistance studies have been performed on the RHEPP-I facility at Sandia National Laboratories testing 2024-T3 aluminum and sensitized 304 stainless steel. In this work, samples were treated using a $700 \mathrm{keV}$, $60 \mathrm{~ns}$, mixed proton-carbon beam at $2-3 \mathrm{~J} / \mathrm{cm}^{2}$. Corrosion resistance of the treated aluminum alloy surfaces has been assessed by electrochemical testing and by salt spray exposure testing. Treated alloys tested thus far include 2024-T3 (Al-4.4 Cu-1.5 Mg-0.6 Mn), 6061-T6 (Al-1.0 Mg-0.6 Si), and 7075-T6 (Al-5.6 Zn-2.5 Mg-1.6 Cu). Electrochemical tests used include anodic polarization and electrochemical impedance spectroscopy (EIS) conducted in an aerated aqueous $0.5 \mathrm{M} \mathrm{NaCl}$ solution. Exposure testing has been conducted at controlled temperatures in a saturated salt fog environment per ASTM B117. Anodic polarization of 2024-T3 has shown that passive current densities are reduced and pitting potentials are shifted to more positive potentials indicating improved resistance to localized corrosion. Figure 5 illustrates these results.
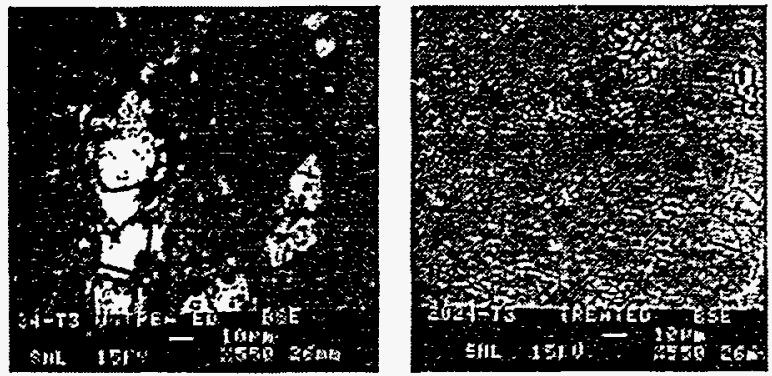

Figure 5. A 168 hour salt fog test (ASTM B117) of untreated and treated samples of Aluminum 2024-T3 shows resistance to pitting due to IBEST treatment.

Pitting resistance was also seen in tests of $316 \mathrm{~F}$ and $316 \mathrm{~L}$ stainless steel samples subjected to chloride ion solutions of $50-5000 \mathrm{ppm}$ in $\mathrm{pH} 2 \mathrm{H}_{2} \mathrm{SO}_{4}$. IBEST-treated surfaces resisted pitting at chloride concentrations of 10-100 times that at which untreated materials began to pit. This improvement was ascribed to the greatly reduced number of defects and second phase particles on the surface of the treated samples.

Results from experiments comparing IBEST-treated and untreated sensitized 304 stainless steel show that IBEST is effective in preventing etching at the grain boundaries of sensitized steel surfaces. Such etching takes place at welds in stainless steel where heating of the material has resulted in the migration of the protective chrome from 
the grain boundaries to grain interiors, leaving the grain boundaries unprotected and subject to environmental attack. In this experiment the 304 stainless steel samples were sensitized by exposure to $600^{\circ} \mathrm{C}$ for 100 hours. The treated samples were treated on the RHEPP-I facility using the same beam described above but at intensities of 3-5 J/cm ${ }^{2}$. Treated and untreated samples were then subjected to $0.5 \mathrm{M} \mathrm{H}_{2} \mathrm{SO}_{4}$ plus $0.01 \mathrm{M} \mathrm{KSCN}$.

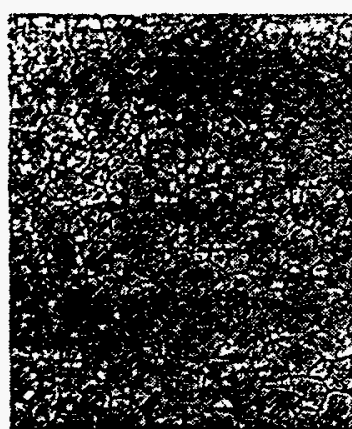

Untreated

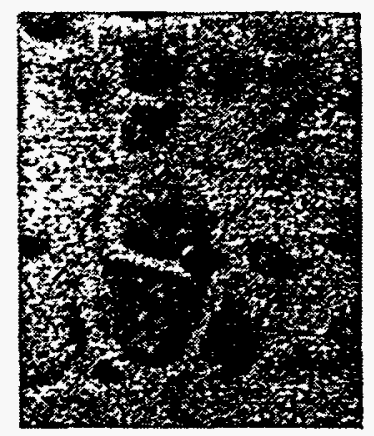

Treated
Figure 6. Comparison between treated and untreated, sensitized 304 stainless steel samples after exposure to $0.5 \mathrm{M} \mathrm{H}_{2} \mathrm{SO}_{4}$ plus $0.01 \mathrm{M} \mathrm{KSCN}$.

The results, shown in Figure 6, show that grain boundary was eliminated in the IBEST-treated sample. Anodic polarization tests showed that the overall corrosion rate decreased by a factor of 40 .

In other experiments preliminary results indicate that we have succeeded in mixing a $35 \mathrm{~nm}$ layer of chrome into an underlying iron surface to produce an extremely corrosion resistant "stainless steel" layer extending at least a micron deep.

\section{Production and Modification of Amorphous Metal Surfaces}

IBEST can produce or modify amorphous metal surfaces by rapid melt and resolidification. The rapid solidification rates used in the IBEST process $\left(10^{9} \mathrm{~K} / \mathrm{sec}\right)$ is much faster than those used in the production of commercial amorphous magnetic material (typically $10^{6} \mathrm{~K} / \mathrm{sec}$ ). This may allow the IBEST process to be used to modify the rough, "wheel side" of METGLAS (registered trademark of Allied Signal Corporation for amorphous metallic alloys) ferromagnetic alloy ribbon. This is important because this rough surface, formed by contact with the cooled wheel in a melt-spinning quenching process, makes it difficult to use interleaved insulation layers, limits the production of very thin material for high frequency applications, and provides surface topology that may contribute to low ductility in thick layers of the material. We tested the ability of IBEST to melt and resolidify this material using METGLAS $2605 \mathrm{CO}$. The results, shown in Figure 7, indicate that IBEST can provide smooth "wheel side" surfaces that are resolidified at rates approximately 1000 times faster than the original forming process. X-ray diffraction results showed no difference between the original and the treated material.
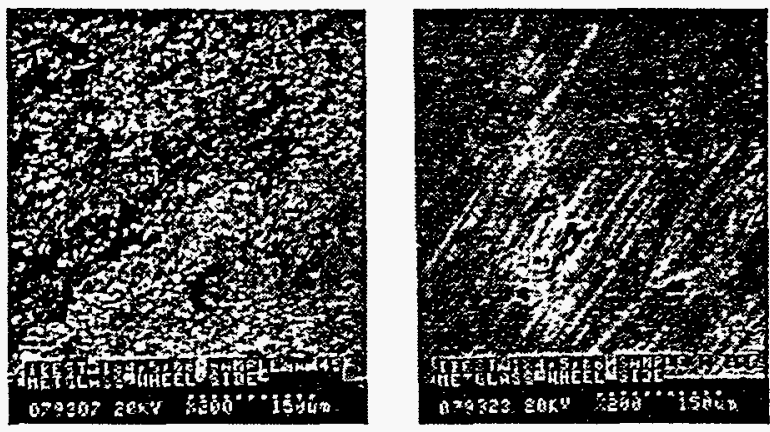

Figure 7. IBEST can smooth amorphous ferromagnetic material using much more rapid resolidification than the original forming process. The picture on the left is the rough, "wheel side of METGLAS 2605 CO (manufactured by Allied Signal). The right picture is the same material with 1-2 J/cm $\mathrm{cm}^{2}$ IBEST treatment.

Controlled Melt and Resolidification of an Alumina Surface

On the LION accelerator at Cornell University we treated a polished $\mathrm{Al}_{2} \mathrm{O}_{3}$ sample with a single pulse at a level of $10-20 \mathrm{~J} / \mathrm{cm}^{2}$ to show controlled melt and resolidification. The result is shown in Figure 8 . This technique shows promise for surface porosity reduction but also shows some microcracking on a 0.1 micron scale. 
Before

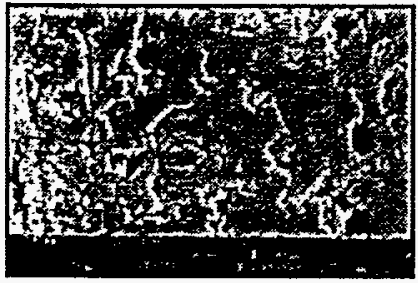

After

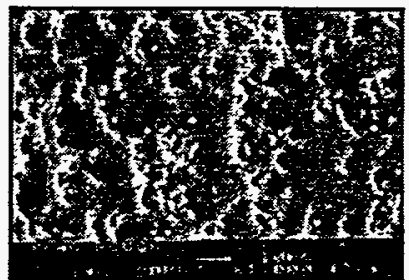

Figure 8. This alumina sample was treated using a single pulse, $0.6-1 \mathrm{MeV}$ mixed proton and carbon beam at $10 \mathrm{~J} / \mathrm{cm}^{2}$. The result shows controlled melt and resolidification of the ceramic surface without serious problems but with some 0.1 micron scale cracking. The width shown is 100 microns.

\section{Surface Cleaning Using IBEST}

Because IBEST treatment raises the surface of materials to very high temperatures, it provides a simple way to remove volatile material such a hydrocarbons from surfaces. We have done initial tests of this technique on RHEPP-I by coating a 304 stainless steel surface with machining oil, then treating the surface with and ion beams intensity of $1-2 \mathrm{~J} / \mathrm{cm}^{2}$. This treatment resulted in the removal of the $100 \mathrm{~nm}$ thick hydrocarbon coating, as shown by the x-ray photo emission spectroscopy results in Figure 9 below. The remaining $4 \mathrm{~nm}$ of carbon seen on the sample is normal atmospheric contamination and was present because no special care was taken to protect the sample after treatment.

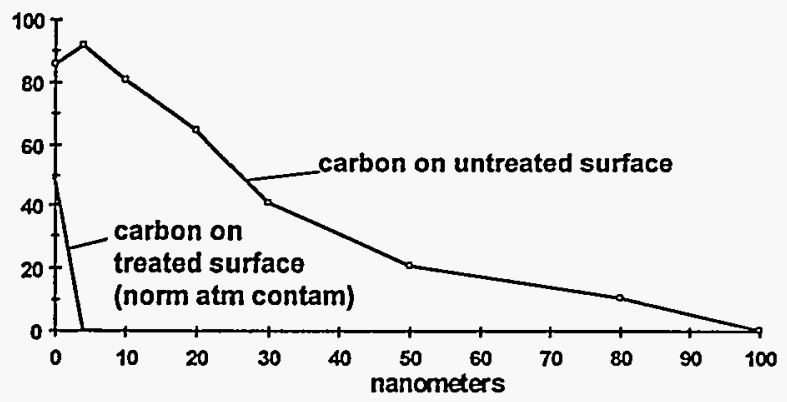

Figure 9. XPS results show removal of hydrocarbon layer from a stainless steel 304 surface by a $1-2 \mathrm{~J} / \mathrm{cm}^{2}$ ion beam.

\section{IBEST-Assisted Film Deposition}

The use of intense pulsed ion beams to produce congruent evaporative deposition of polycrystalline and amorphous films has been demonstrated ${ }^{8,16,17,18}$ in many laboratories. The technology developed for IBEST is especially well suited for this application due to its ability to support high average power delivery resulting in the ability to deposit films at the rate of 10-20 microns per minute. Such high deposition rates sometimes result in poor quality, porous films. This problem can be solved by using our IBEST capability to melt and resolidify the films after each few microns are deposited.

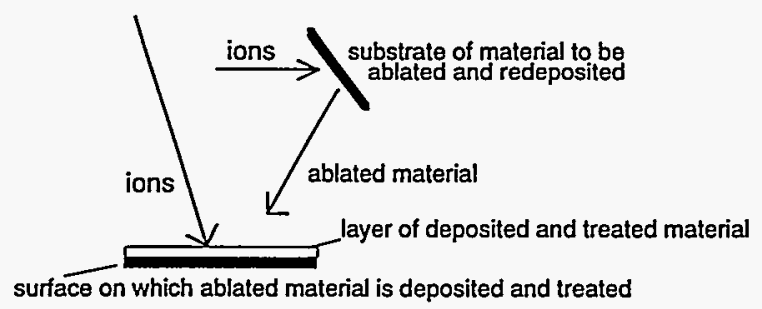

Figure 10. IBEST-assisted deposition can rapidly build up thick layers of material that is hard, corrosion and wear resistant, and defect-free. 
This technique, illustrated in Figure 10, should produce defect-free, hard, wear and corrosion resistant films that can be grown to any thickness.

\section{Enabling Technologies For IBEST}

Until recently pulsed ion beams have not been considered a viable technology for routine materials processing applications because of their inability to deliver the multi-kilowatt average powers with long component lifetimes needed for commercial processing applications. During the past few years there has been significant progress in two complementary technologies that now enable the design of $5-500 \mathrm{~kW}$ average power, $>10^{8}$ shot lifetime ion beam surface treatment systems for materials processing.

The first of these advances is the development of a compact, low impedance, electrically efficient, repetitively pulsed, magnetically switched pulsed power system capable of $10^{9}$ pulse component lifetimes. This prototype system (Figure 11), the Repetitive High Energy Pulsed Power I(RHEPP-I) facility ${ }^{19}$ (0.8 MV matched voltage, $35 \Omega, 60 \mathrm{~ns} F W H M$ pulse duration, $120 \mathrm{~Hz}$ repetition frequency), began operation this year at Sandia National Laboratories. This new facility, the first of its kind in the world, is designed to operate continuously at $120 \mathrm{~Hz}$, delivering $150 \mathrm{~kW}$ average power. This system has demonstrated operation at $50 \%$ electrical efficiency from the wall plug to energy delivered to a matched load. RHEPP-I is also designed to allow operation at reduced pulse rates or in single pulse mode if desired. Its capability to efficiently produce high average power, high voltage electrical pulses using a compact design is a breakthrough for the commercial application of pulsed power.

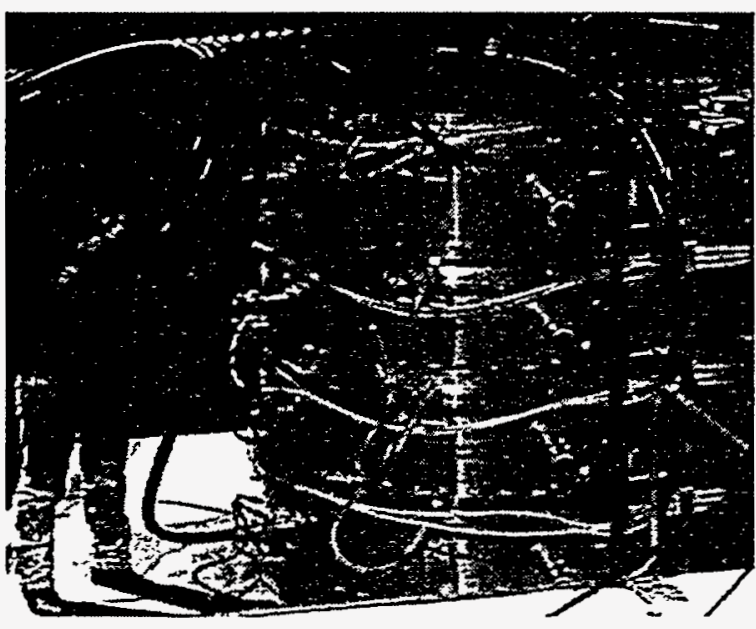

Figure 11. The RHEPP accelerator is designed to operate at $120 \mathrm{~Hz}$, delivering an average power of $150 \mathrm{~kW}$ in $0.8 \mathrm{MV}, 60 \mathrm{~ns}$ pulses.

The second advance is an ion beam system that is capable of operating repetitively and efficiently to transform the pulsed power of RHEPP into an ion beam. An ion beam system capable of operating at repetitive pulse rates of $100 \mathrm{~Hz}$ in 10 pulse burst mode (active cooling was not part of the design) was demonstrated ${ }^{12}$ at the Cornell University Laboratory of Plasma Studies. An improved version of this system is now being fielded on the RHEPP facility at Sandia for operation in burst mode. This system, the Magnetically-confined Anode Plasma (MAP) ion source, shown in Figure 12, is based on the concept of drawing ions from a single species plasma anode rather than the solid, flashover anode used in standard single pulse ion beam systems. The plasma can be formed from any gas ion. 


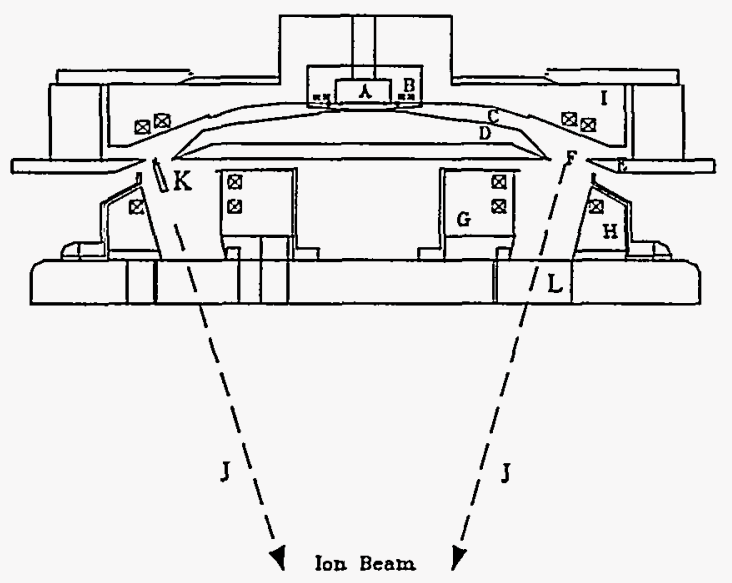

Figure 12. The MAP diode for RHEPP1. The fast puff gas valve (A) with the puff valve magnetic field coil (B); the supersonic gas nozzle (C); The inner (D) and outer (E) anode flux excluders; the gas annulus for plasma formation $(F)$; the inner $(G)$ and outer $(\mathrm{H})$ cathode slow magnetic field coils; fast anode magnetic field coils (I); the ion beam propagation path (J); cathode annulus gap (L).

In experiments conducted to date on RHEPP-I, we have used the MAP diode to produce active anode plasmas using hydrogen, helium, nitrogen, and air. These results and the optimum operating parameter ranges we determined are consistent with those used in earlier experiments at Cornell University. 12

The MAP ion beam system produces an annular beam which is brought to a broad focus symmetric about the axis shown in the figure. In the cathode (ground potential) electrode assembly, slow (100 $\mu$ s risetime) magnetic field coils $(\mathrm{G}$ and $\mathrm{H})$ produce magnetic flux which provides the magnetic insulation of the accelerating gap between the cathode and the anode electrode assembly ( $D$ and $E$ ) connected to the output of the RHEPP generator. The ion source that supplies ions to the accelerating gap is contained within the anode assembly. The MAP source operates in the following way: a fast gas valve (A) on the axis of the anode assembly produces a rapid (200 $\mu$ s) gas puff which is delivered through a supersonic nozzle (C) to produce a highly localized volume of gas directly in front of the surface of a fast-driving coil (I) located in an insulating support structure. After preionization by a $2 \mu \mathrm{s}$ induced electric field, the fast coil is energized, inducing a loop voltage of $20 \mathrm{kV}$ on the gas volume, driving a breakdown to full ionization, and moving the resulting plasma toward the flux-excluding anode fieldshapinelectrodes (D and $E$ ) in about $1.5 \mu \mathrm{s}$, to

form a thin magnetically-confined plasma layer $(F)$. The RHEPP-I pulse is then applied to the anode assembly, accelerating ions from this plasma layer to form the ion beam. The magnetic flux surfaces at the time of beam extraction are shown in Figure 13. The beam propagates in vacuum to a broad focal area at the target plane where material samples are placed for treatment. This new MAP diode geometry used on RHEPP-I incorporates several new features that improve control over preionization and plasma positioning and allow extraction of a nonrotating beam for more efficient treatment.

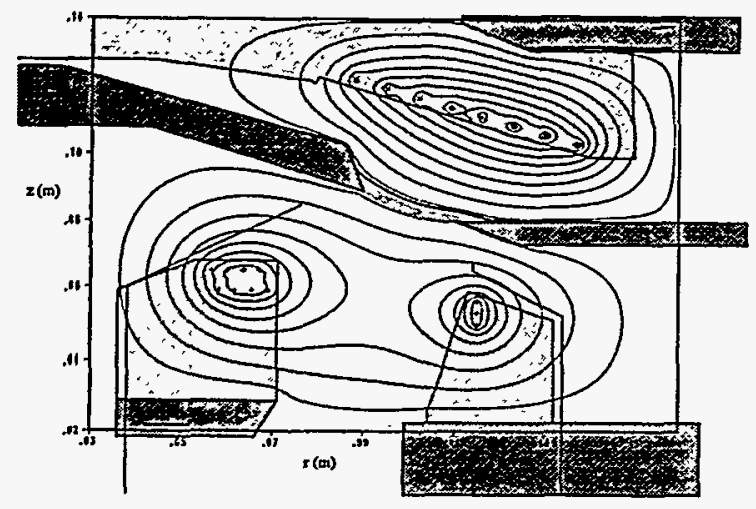

FIGURE 13. DATHETA Simulation showing the combined slow and fast magnetic field profile. The lower electrode is the annular cathode, the center annular electrode is tha anode with a shaded region illustrating the plasma postion, the upper shaded region is the fast magnetic field coil that induces electric fields in the gas to produce ionization, then pushes the plasma into position in the annular gap in the anode. 


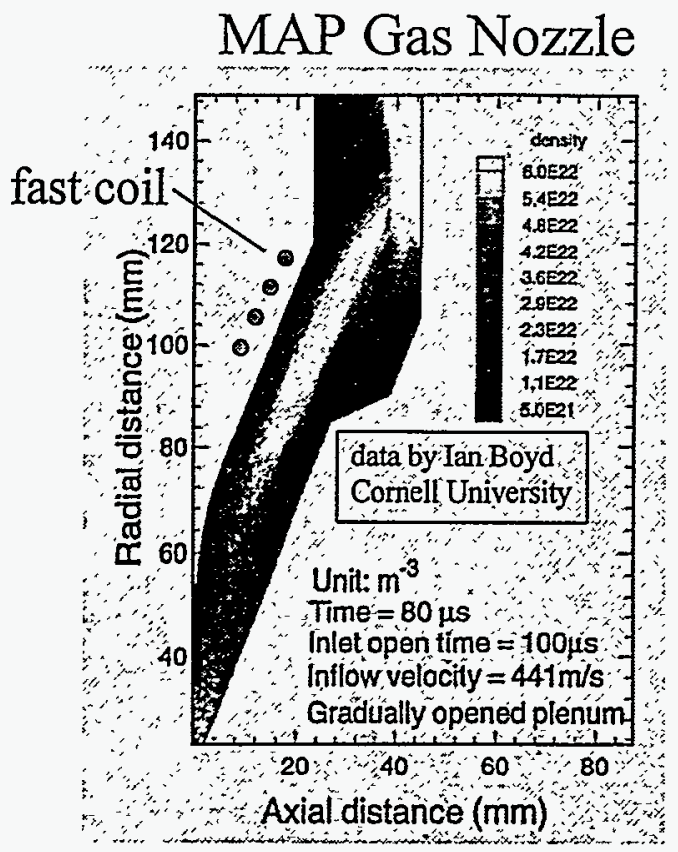

Figure 14. Two-dimensional calculations of the supersonic gas flow from the puff valve to the position where the gas is ionized show a spatially well-defined region of relatively dense gas that is well separated from the acceleration gap.

Our ability to design MAP systems is also improved by a new ability to calculate the performance of the gas puff system including the supersonic nozzle. Figure 14 shows the results of a 2-d time dependent calculation of the gas flow in our present system. These calculations, showing a well defined $60 \mathrm{mtorr}$ gas puff that remains well separated from the acceleration gap, are in rough agreement with preliminary fast gauge measurements. Further optimization of our MAP geometry and systems are being done based on both calculations and experiments.

\section{Conclusions}

We have demonstrated that Ion Beam Surface Treatment (IBEST) can significantly alter the microstructures of the near surface region of materials and thus the material properties. The effects of IBEST include hardening, corrosion resistance, polishing and cleaning. The developing repetitive pulsed power and beam technology on which IBEST is based, is a new capability that can provide new ways to cost-effectively treat surfaces in a wide variety of applications

\section{Acknowledgement}

This work was supported by the United States Department of Energy under Contract Number DE-AC0494AL85000 and by DOE's Advanced Energy Projects Division/Office of Basic Energy Sciences.

\section{References}

1. E. M. Breinan, B. H. Kear, L. E. Greenwald, and C. M. Banas, "Laser Glazing, a New Process for Production and Control of Rapidly Chilled Metallurgical Microstructures," Lasers in Modern Industry, (Dearborn, Michigan 1979), 147-166.

2. H.-W. Bergmann, B. L. Mordike, "Laser and Electron-Beam Melted Amorphous Layers," I. Mat. Sci., (1981), 863-869.

3. R. Fastow, "Pulsed Ion Beam Surface Modification of Materials", Ph.D. thesis, Cornell University, 1985.

4. R. Fastow, Y. Maron, and J. Mayer, "Pulsed ion beam melting of silicon", (Phys. Rev. B, 31,893 (1985)

5. G. E. Remnev, and V. A. Shulov, "Practical Applications of High-Power Ion Beams," 9th International Conference on High-Power Particle Beams, Washington, D.C., 5/25-29, 1992.

6. S. A. Chistjakov, A. M. Gagarin, R. G. Koishibaev, Yu Yu Rjuchkov, V. A. Kuzminikh, V. M. Milutin, V. A. Pirogov, V. A. Perov, A. D. Pogrebnjak, S. V. Plotnik, G. E. Remnev, Yu G. Rusin, and V. P. Janovskii, 
"Ion Mixing of Near Surface Layers in Au-Cu, Cu-Mo Systems Irradiated by HPIB," Physics Letters, Vol. 131, No. $1,8 / 1,1988,73-77$.

7. V. L. Kutuzov, M. Yu. Ovsyannikov, I. G. Romanov, A. D. Pogrebnyak, and G. E. Remnev, "Mechanical and Frictional Properties of Tool Steels Exposed to HPIB Irradiation," Mechanical and Frictional Properties of Tool Steels, 11/8, 1988, 361-364.

8. Y. Shimotori, M. Yokoyama, H. Isoḅe, S. Harada, K. Masugata, K. Yatsui, JAP 63, 968 (1988).

9. A. D. Pogrebnyak, "Metastable States and Structural Phase Changes in Metals and Alloys Exposed to High Power Ion Beams", Phys. Stat. Sol. (a) 117, 17 (1990)

10. J. B. Greenly, M. Ueda, G. D. Rondeau and D. A. Hammer, "Magnetically Insulated Ion Diode with a GasBreakdown Plasma Anode," J. Appl. Phys 63, 1872 (1988).

11. J. B. Greenly, L. Brissette, A. Dunning, S. C. Glidden, D. A. Hammer and W. A. Noonan, "Plasma Anode Ion Diode Research at Cornell: Repetitive Pulse and 0.1 TW Single-Pulse Experiments," Proceedings of the 8th Intl. Conf. on High Power Particle Beams, B. N. Breizman and B. A. Knyazev, Eds., Novosibirsk, 1990 (World Scientific), p. 199.

12. W. A. Noonan, Ph.D. thesis, Cornell University, 1993.

13. M. Ueda, J. B. Greenly, G. D. Rondeau and D. A. Hammer, Rev. Sci. Instr. 64(10), 2737 (1993).

14. G. Rondeau, Ph.D. Thesis, Cornell University, 1989.

15. R. W. Stinnett, R. G. Buchheit, F. A. Greulich, C. R. Hills, A. C. Kilgo, D. C. McIntrye, J. B. Greenly, M. O. Thompson, and D. J. Rej, "Thermal Surface Treatment Using Intense, Pulsed Ion Beams," Mat. Res. Soc. Symp. Proc. Vol. 316, p521-532.

16. D. J. Rej, R. R. Bartsch, H. A. Davis, R. J. Fael, D. C. Gautier, J. B. Greenly, I. Henins, T. W. Linton, R. E. Muenchausen, W. J. Waganaar," Intense Ion Beam Research at Los Alamos", Proceedings of the 9th Intl. Conf. on High-Power Beams, David Mosher and Gerald Cooperstein, Eds., Washington D. C., 1992 (NTIS PB92-206168), Vol. I, p. 88

17. J. H. Scofield, J. Electron Spectroscopy $\underline{8}, 129$ (1976).

18. O. I. Goncharov et al., Proc. 8th Intern. Conf. on High-Power Particle Beams, B. N. Breizman, B. A. Knyazev Ed. (World Scientific Publishing Co., 1991), Vol. II, p 1243.

19. H. C. Harjes, K. J. Penn, K. W. Reed, C. R. McClenahan, G. E. Laderach, R. W. Wavrik, J. L. Adcock, M. E. Butler, G. A. Mann, G. E. Pena, G. J. Weber, D. VanDeValde, L. E. Martinez, D. Muirhead, P. D. Kiekel, D. L. Johnson, E. L. Neau, "Initial results from the RHEPP module", Proc. 9th Int. Conf. on High Power Particle Beams, Washington D.C., May 25-29, 1992, 333-340.

\section{DISCLAIMER}

This report was prepared as an account of work sponsored by an agency of the United States Government. Neither the United States Government nor any agency thereof, nor any of their employees, makes any warranty, express or implied, or assumes any legal liability or responsibility for the accuracy, completeness, or usefulness of any information, apparatus, product, or process disclosed, or represents that its use would not infringe privately owned rights. Reference herein to any specific commercial product, process, or service by trade name, trademark, manufacturer, or otherwise does not necessarily constitute or imply its endorsement, recommendation, or favoring by the United States Government or any agency thereof. The views and opinions of authors expressed herein do not necessarily state or reflect those of the United States Government or any agency thereof. 